\title{
Electrochemical evidence of malonate specific sorption to hematite
}

\author{
KAROLINA KĘDRA-KRÓLIK' TAJANA BEGOVIĆ, \\ MARZENA PRUS, ${ }^{\prime}$ DANIJEL NAMIESNIK, ${ }^{2}$ KAROLINA \\ SZYMANEK, ${ }^{3}$ WOJCIECH PIASECKI, ${ }^{3}$ PIOTRZARZYCKI ${ }^{4}$
}

Institute of Physical Chemistry, Polish Academy of Sciences, Warsaw, Poland; kkedrakrolik@ichf.edu.pl

Department of Chemistry, Faculty of Science, University of Zagreb, Croatia

${ }^{3}$ Department of Chemistry and Biochemistry, AWF, Warsaw

"Energy Geosciences Division, Lawrence Berkeley National

Laboratory, Berkeley, CA

The environmental iron cycling is governed by several geochemical processes, including dissolution/precipitation, sorption, exchange, redox and photochemical reactions [1]. However, our current knowledge of how organic matter interactions with minerals affect iron bioavailability is limited, in part due to limited experimental informaton on binding mechanism of organic molecules.

In this work, we present an electrochemical study of the effect of malonic acid interactions with hematite on the electrical double layer properties. The electrokinetic [2,3], potentiometric [3-5] measurements show that malonate adsorbs specifically between $\mathrm{pH} 3$ and 8.3. We show that isoelectric point shifts towards lower $\mathrm{pH}$-values, whereas the point of zero charge shifts towards higher $\mathrm{pH}$ values as the malonate concentration increases - a clear evidence of the specific sorption [5]. By combining, aqueous and surface speciation calculations, we show that malonate can adsorb as either monodentate or bidentate complexes, with a varying degrees of protonation.

Our findings are relevant for the understanding of the role of organic matter interactions with iron oxides in the elemental cycling of iron, as well as heavy and radioactive cations in the environment.

[1] Gu B., et al. (1994). Environ. Sci. Technol. 28, 38-46.

[2] Kędra-Królik K. et al. (2017) J. Colloid Interface Science 488, 218-224

[3] Toczydłowska D. et al. (2015) Phys. Chem. Chem. Phys 17, 26264-26269.

[4] T. Preocanin, N. Kallay, J. Colloid Interface Science, 299 (2006) 772-776

[5] Zarzycki P. et al. (2010) Croat. Chem . Acta 83, 457-474. 